\title{
Hubungan Pengetahuan Dan Sikap Dengan Penggunaan Alat Pelindung Diri (APD) Pada Pekerja Bongkar Muat di Pelabuhan Pantoloan
}

\author{
Sapriana \\ Poltekkes Kemenkes Palu \\ Email korespondensi: saprianasyamsuddin@yahoo.co.id
}

\begin{abstract}
The lower the frequency of using Personal Protective Equipment (PPE), the greater the chance of work accident. Workers' knowledge and attitudes greatly influence the use of PPE. This study aimed to analyze relationship between knowledge and attitudes with the use of PPE on loading and unloading workers at the Port of Pantoloan. This was an analytical study with cross sectional approach, population 110 workers, sample 52 workers, using accidental sampling. Univariate analysis resulted $61,5 \%$ workers had good knowledge about the use of PPE, 76,9\% workers were positive about the use of PPE, and most workers did not use PPE while working (88,5\%). Fisher Exact test resulted that respondents' good knowledge of personal protective equipment was related to the behavior of using PPE $(p=0,045)$, and positive attitude of respondents about PPE was not related to the behavior of using it $(p=$ 0.189). Conclusions: good knowledge about PPE related to the behavior of using it, positive attitude about PPE was not related to the behavior of using it. It is recommended to conduct qualitative research to help understand workers 'attitudes and thoughts about the use of $P P E$, in addition to related parties, in order to make maximum efforts to increase workers' awareness of Occupational Health and Safety (K3), especially the use of PPE
\end{abstract}

Keywords : Knowlede, attitude, PPE, worker

\begin{abstract}
ABSTRAK
Semakin rendah frekuensi penggunaan Alat Pelindung Diri (APD) maka semakin besar kesempatan terjadinya kecelakaan kerja. Pengetahuan dan sikap pekerja sangat berpengaruh terhadap penggunaan APD. Penelitian ini bertujuan untuk menganalisis hubungan pengetahuan dan sikap dengan penggunaan APD pada pekerja bongkar muat di Pelabuhan Pantoloan. Penelitian ini merupakan penelitian analitik dengan pendekatan cross sectional, populasi 110 pekerja, sampel 52 pekerja, menggunakan metode accidental sampling. Hasil analisis univariat menunjukkan $61,5 \%$ pekerja memiliki pengetahuan baik tentang penggunaan APD, 76,9\% pekerja bersikap positif tentang penggunaan APD, dan sebagian besar pekerja tidak menggunakan APD saat bekerja (88,5\%). Hasil uji Fisher Exact menunjukkan pengetahuan responden yang baik tentang alat pelindung diri berhubungan dengan perilaku penggunaan APD saat bekerja $(p=0,045)$, dan sikap responden yang positif tentang alat pelindung diri tidak berhubungan dengan perilaku penggunaan APD saat bekerja $(p=0,189)$. Kesimpulan: a) Pengetahuan yang baik tentang alat pelindung diri berhubungan dengan perilaku penggunaan APD saat bekerja; b) Sikap positif tentang alat pelindung diri tidak berhubungan dengan perilaku penggunaan APD saat bekerja. Disarankan melakukan penelitian kualitatif untuk membantu memahami sikap dan pemikiran pekerja tentang penggunaan APD, selain itu kepada pihak terkait, agar berupaya maksimal meningkatkan kesadaran pekerja tentang Kesehatan dan Keselamatan Kerja (K3) khususnya penggunaan APD.
\end{abstract}

Kata kunci: Pengetahuan, sikap, penggunaan APD, pekerja 


\section{PENDAHULUAN}

Tidak menggunakan Alat Pelindung Diri (APD) saat bekerja merupakan salah satu contoh perilaku tidak aman. Perilaku tidak aman dapat menimbulkan terjadinya kematian ataupun kerugian. Semakin rendah frekuensi penggunaan APD maka semakin besar kesempatan terjadinya kecelakaan kerja. ${ }^{1}$ Penggunaan alat pelindung diri (APD) berhubungan secara signifikan dengan kecelakaan kerja). ${ }^{2}$ Kurangnya kesadaran menggunakan APD dapat disebabkankan oleh rendahnya pengetahuan dan sikap karyawan tentang suatu teknik keselamatan dan kesehatan kerja di lingkungan kerja. Faktor manusia (pekerja) memiliki pengaruh untuk terjadinya kecelakaan kerja. Tingkat pengetahuan rendah dan kelelahan memiliki risiko lebih tinggi untuk terjadinya kecelakaan kerja. ${ }^{3}$

Menurut International Labour Organization (ILO) terdapat 2,78 juta pekerja meninggal setiap tahun karena kecelakaan kerja. Sekitar 2,4 juta $(86,3 \%)$ dari kematian ini di karenakan penyakit akibat kerja, sementara lebih dari 380.000 (13,7\%) dikarenakan kecelakaan kerja. ${ }^{4}$ Kasus kecelakaan kerja di Indonesia menunjukan trend penurunan pada tiga tahun terakhir, 153.044 kasus (tahun 2020), 155.327 kasus (tahun 2019), dan 173.415 kasus (tahun 2018), 68,5 persen terjadi di dalam lingkungan kerja. ${ }^{5}$ Berdasarkan data BPJS Ketenagakerjaan (2019), di Propinsi Sulawesi Tengah pada Tahun 2019 telah terjadi 691 kasus kecelakaan kerja. ${ }^{6}$

Karyawan yang patuh memiliki pengetahuan dan kesadaran untuk melindungi dirinya terhadap bahaya keselamatan kerja dan akan berperilaku aman dalam melaksanakan pekerjaannya, sebaliknya pekerja yang tidak patuh akan cenderung melakukan kesalahan dalam setiap proses kerja karena tidak mematuhi standar dan peraturan yang ada. UndangUndang RI No. 36 tahun 2009 terkait kesehatan kerja pasal 164, menyebutkan bahwa usaha kesehatan kerja ditunjukkan agar menjaga pekerja untuk kehidupan yang lebih sehat dan bebas dari gangguan kesehatan, sehingga bebas dari dampak negatif. ${ }^{7}$ Selain itu Undangundang RI No. 13 tahun 2013 menyatakan bahwa karyawan wajib dilindungi dari aspek kesejahteraan, kesehatan dan keselamatan berupa kesehatan jiwa maupun kesehatan fisik pekerja. $^{8}$

Pengetahuan responden yang baik tentang alat pelindung diri berhubungan dengan perilaku penggunaan alat pelindung diri saat bekerja, dan sikap responden yang positif tentang alat pelindung diri berhubungan dengan perilaku penggunaan alat pelindung diri saat bekerja. Pengetahuan tentang pentingnya penggunaan alat pelindung diri merupakan hal yang harus di ketahui oleh seluruh pekerja agar terhindar dari penyakit akibat kerja maupun insiden kecelakaan kerja. Cara kerja yang mengabaikan anjuran tentang penggunaan alat pelindung diri akan merugikan kesehatan dan keselamatan kerja dari pekerja yang bersangkutan. Pekerja perlu di beri pemahaman agar insiden yang dapat di cegah dengan penggunaan alat pelindung diri dapat di minimalisir.

Berdasarkan penelitian pendahuluan yang dilakukan peneliti, diperoleh informasi bahwa jumlah pekerja yang terdaftar di Koperasi Tenaga Kerja Bongkar Muat (TKBM) adalah sebanyak 110 pekerja. Aktifitas yang dilakukan berupa memindahkan, mengangkat atau mengangkut barang dari kendaran masuk ke dalam kapal, dan lebih banyak menggunakan tenaga pekerja. Hasil observasi peneliti, beberapa pekerja tidak menggunakan Alat Pelindung Diri (APD) secara lengkap seperti, sarung tangan, masker, baju kerja, helm/topi kerja dan sepatu kerja karena merasa tidak nyaman dan mengganggu saat melakukan pekerjaan, padahal alat pelindung diri merupakan kelengkapan yang wajib di gunakan saat bekerja sesuai bahaya dan risiko kerja untuk menjaga keselamatan pekerja itu sendiri dan orang di sekelilingnya.

Berdasarkan uraian tersebut, maka dilakukan penelitian yang bertujuan diketahuinya hubungan pengetahuan dan sikap dengan penggunaan APD pada Pekerja Bongkar Muat di Pelabuhan Pantoloan.

\section{METODE PENELITIAN}

Penelitian ini merupakan penelitian analitik dengan pendekatan Cross Sectional. Dilaksanakan pada Bulan Juli - Agustus 2020. Data dikumpulkan dengan cara wawancara 
dan observasi pada pekerja yang terpilih menjadi sampel. Jumlah populasi 110 orang pekerja, sampel sebanyak 52 pekerja. Teknik sampling menggunakan metode accidental sampling. Adapun instrumen penelitian berupa kuesioner, dan angket. Selanjutnya data dianalisis dengan Chi square test pada derajat kepercayaan 95\% (alpha 0,05).

\section{HASIL PENELITIAN}

Tabel 1. Distribusi Responden Menurut Umur, Pendidikan Terakhir, Jenis Kelamin, Pengetahuan, Sikap dan Penggunaan APD

\begin{tabular}{cllcc}
\hline No. & Karakteristik & Kategori & $\mathbf{n = 5 2}$ & $\%$ \\
\hline 1 & Umur (tahun) & $25-35$ & 7 & 13.5 \\
& & $36-45$ & 6 & 11.5 \\
& & $46-55$ & 24 & 46.2 \\
2 & Pendidikan Terakhir & $56-65$ & 15 & 28.8 \\
& & tidak sekolah & 1 & 1.9 \\
& & SD / sederajat & 15 & 28.8 \\
3 & Jenis Kelamin & SMP / sederajat & 17 & 32.7 \\
4 & Pengetahuan & SMA / sederajat & 19 & 36.5 \\
& & laki - laki & 52 & 100.0 \\
5 & Sikap & baik & 32 & 61.5 \\
& & kurang & 20 & 38.5 \\
6 & Penggunaan APD & positif & 40 & 76.9 \\
& & negatif & 12 & 23.1 \\
& & menggunakan & 6 & 11.5 \\
& & tidak menggunakan & 46 & 88.5 \\
\hline
\end{tabular}

Sumber: Data Primer, 2020

Tabel 1 menunjukkan bahwa 61,5\% pekerja memiliki pengetahuan baik tentang penggunaan APD, 76,9\% pekerja bersikap positif tentang penggunaan APD, dan sebagian besar pekerja tidak menggunakan APD saat bekerja (88,5\%). Dari 52 responden, 36,5\% (19 responden) atau sebagian besar berpendidikan SMA/sederajat, 100\% laki-laki, dan 46,2\% berumur 46-55 tahun.

Tabel 2. Hubungan Pengetahuan dan Sikap dengan Penggunaan APD pada Pekerja Bongkar Muat di Pelabuhan Pantoloan

\begin{tabular}{|c|c|c|c|c|c|c|}
\hline \multirow{3}{*}{ No. } & \multirow{3}{*}{$\begin{array}{l}\text { Variabel } \\
\text { Penelitian }\end{array}$} & \multicolumn{4}{|c|}{ Penggunaan APD } & \multirow{3}{*}{ p-value } \\
\hline & & \multicolumn{2}{|c|}{ Menggunakan } & \multicolumn{2}{|c|}{ Tidak Menggunakan } & \\
\hline & & $\mathbf{n}$ & $\%$ & $\mathbf{n}$ & $\%$ & \\
\hline \multirow[t]{3}{*}{1} & Pengetahuan & & & & & \\
\hline & Baik & 6 & 100,0 & 26 & 56,5 & 0,045 \\
\hline & Kurang & 0 & 0,0 & 20 & 43,5 & \\
\hline \multirow[t]{3}{*}{2} & Sikap & & & & & \\
\hline & Positif & 6 & 100,0 & 34 & 73,9 & 0,189 \\
\hline & Negatif & 0 & 0,0 & 12 & 26,1 & \\
\hline
\end{tabular}

Sumber : Data Primer, 2020

Tabel 2 menunjukkan bahwa semua responden yang berpengetahuan baik dan bersikap positif tentang APD menggunakan alat pelindung diri saat bekerja. Hasil fisher exact test (1sided) menunjukkan bahwa nilai $a(0,05)>p(0,045)$, yang berarti bahwa pengetahuan responden yang baik tentang alat pelindung diri berhubungan dengan perilaku penggunaan alat pelindung diri saat bekerja, dan nilai $\alpha(0,05)<p(0,189)$, yang berarti bahwa sikap responden yang positif tentang alat pelindung diri tidak berhubungan dengan perilaku penggunaan alat pelindung diri saat bekerja. 


\section{PEMBAHASAN}

\section{Hubungan Pengetahuan dengan Penggunaan APD}

Ada beberapa faktor yang mempengaruhi pengetahuan yang baik. Pertama, yaitu pendidikan, semakin tinggi pendidikan seseorang semakin mudah pula bagi mereka untuk menerima informasi dan pada akhirnya makin banyak pengetahuan yang mereka miliki. Kedua, kemudahan seseorang untuk memperoleh informasi dapat membantu mempercepat seseorang untuk memperoleh pengetahuan yang baru. ${ }^{9}$ Berdasarkan tabel 1 dapat diketahui bahwa dari 6 responden yang menggunakan APD saat bekerja 100\% berpengetahuan baik tentang alat pelindung diri, dan tidak satu pun responden yang menggunakan APD saat bekerja pengetahuannya kurang. Dari 46 responden yang tidak menggunakan APD saat bekerja, $43,5 \%$ atau 20 responden berpengetahuan kurang tentang alat pelindung diri.

Hasil penelitian ini sejalan dengan penelitian Nurzaidah dengan judul hubungan pengetahuan dan sikap dengan penggunaan APD Pada pekerja kasur di Desa Dalaka Kecamatan Sindue Kabupaten Donggala. yang menyimpulkan ada hubungan antara pengetahuan dengan pemakaian Alat Pelindung Diri (APD) dengan nilai $p$-value $=0,000 .^{10}$ Berbeda dengan penelitian yang dilakukan Heni Fa'riatul Aeni dengan judul Hubungan pengetahuan dan Sikap dengan Praktik Penggunaan Alat Pelindung Diri (APD) pada Petani Pengguna Pestisida di Desa Sigambir Kecamatan Brebes Kabupaten Brebes Tahun 2018 yang menyimpulkan tidak ada hubungan antara pengetahuan terhadap praktik pemakaian APD pada petani pengguna pestisida dengan nilai $p$-value $=0,487$. $^{11}$

Faktor penentu atau determinan perilaku manusia sulit untuk dibatasi karena perilaku merupakan resultan dari beberapa faktor, baik internal maupun eksternal (lingkungan), secara lebih terinci, perilaku manusia sebenarnya merupakan refleksi dari berbagai gejala kejiwaan, seperti pengetahuan, keinginan, kehendak, minat, motivasi, persepsi, sikap dan sebagainya. Perilaku Pekerja dalam penggunaan APD dipengaruhi banyak faktor, walaupun pengetahuan responden baik atau pekerja mengerti saat berinteraksi dengan benda berat atau alat berat, akan tetapi dalam praktiknya bisa saja tidak sesuai. Faktor lain yang dapat berpengaruh terhadap perubahan atau pembentuk perilaku adalah faktor pendukung (enabling factor) seperti ketersediaan APD. Sebagaimana penelitian Akeza et al, menyimpulkan bahwa pekerja tetap memiliki proporsi respon positif yang lebih tinggi pada pengetahuan dan sikap terhadap bahaya kesehatan kimia dibandingkan pekerja tidak tetap. Namun, praktik dalam penggunaan APD bergantung pada akses atau ketersediaan APD. Pekerja tetap diberikan APD sedangkan pekerja tidak tetap tidak diberikan APD. Penelitian kualitatif dapat membantu untuk memahami sikap dan pemikiran pekerja dan personel administrasi tentang bahaya kimia dan APD. ${ }^{12}$

Penelitian Izudi et al menunjukkan rendahnya penggunaan APD di antara pekerja konstruksi bangunan di Kampala. Dalam analisis bivariat, pengetahuan sebelumnya tentang keselamatan $(p$-value $<0,001)$ signifikan terkait dengan penggunaan APD. Dalam analisis univariabel, responden perempuan menggunakan APD lebih banyak dari responden laki-laki. Responden berusia 31-45 tahun dan 46-60 tahun juga menggunakan APD lebih banyak dibandingkan mereka yang berusia $18-30$ tahun. $^{13}$

\section{Hubungan Pengetahuan dengan Penggunaan APD}

Sikap merupakan predisposisi untuk melakukan atau tidak melakukan suatu perilaku tertentu, sikap lebih mengarah pada suatu proses kesadaran yang sifatnya individual. Sikap yang positif akan memicu seseorang untuk melakukan suatu tindakan. Berdasarkan Tabel 2. dapat diketahui bahwa dari 6 responden yang menggunakan APD saat bekerja 100\% berpengetahuan baik tentang alat pelindung diri, dan tidak satu pun responden yang menggunakan APD saat bekerja pengetahuannya kurang, Dari 46 responden yang tidak menggunakan APD saat bekerja, 43,5\% atau 20 responden berpengetahuan kurang tentang alat pelindung diri. Hasil penelitian ini sejalan dengan hasil penelitian Aeni di Desa Sigambir Kecamatan Brebes Kabupaten Brebes Tahun 2018 yang menyimpulkan tidak ada hubungan antara sikap terhadap praktik pemakaian APD pada petani pengguna pestisida dengan nilai $p$-value $=0,487 .{ }^{11}$ Berbeda dengan penelitian Nurzaidah di Desa Dalaka Kecamatan Sindue 
Kabupaten Donggala, menyimpulkan ada hubungan antara Sikap dengan pemakaian Alat Pelindung Diri (APD) dengan nilai $p$-value $=0,000$. $^{10}$

Sikap merupakan predisposisi untuk melakukan atau tidak melakukan suatu perilaku tertentu, sikap lebih suatu proses kesadaran yang sifatnya Individual. ${ }^{9}$ Suatu sikap belum otomatis terwujud dalam suatu tindakan. Untuk terwujudnya sikap agar menjadi tindakan yang nyata diperlukan beberapa komponen. Tindakan seseorang terhadap stimulus tertentu akan banyak ditentukan oleh bagimana kepercayaan dan perasaannya terhadap stimulus tersebut. Secara biologis, sikap dapat dicerminkan dalam suatu bentuk tindakan, namun tidak pula dapat dikatakan bahwa sikap dan tindakan memiliki hubungan yang sistematis ${ }^{(8)}$. Dari 52 responden, 76,9\% bersikap positif tentang penggunaan APD, akan tetapi pada saat penelitian, peneliti masih mendapatkan pekerja yang bekerja tidak menggunakan APD, tentu saja hal tersebut bertentangan dengan apa yang disampaikan pada saat wawancara. Hasil penelitian menunjukkan sebagian besar responden (88,5\%) tidak menggunakan APD sesuai bahaya dan resiko yang di hadapi saat bekerja.

Penelitian Rostami dkk menemukan bahwa sebagian besar responden tidak memiliki pengetahuan yang memadai. Banyak petani memiliki sikap yang tepat terhadap penggunaan alat pelindung diri. Namun, 37,4\% dari mereka melaporkan bahwa penggunaan alat pelindung diri tidaklah mudah. Praktik petani terhadap penggunaan alat pelindung diri berkorelasi dengan pengetahuan dan sikap mereka $(p<0,001) .{ }^{14}$ Penelitian Bondori et al. menemukan bahwa hampir setengah dari petani tingkat penggunaan APD rendah $(48,3 \%)$, $30,5 \%$ tingkat penggunaan APD sedang dan 21,2\% tingkat penggunaan APD yang tinggi. Perilaku penggunaan APD juga menunjukkan keterkaitan yang positif dengan jumlah anggota rumah tangga yang melek huruf, pengetahuan petani tentang bahaya pestisida, dan penggunaan sumber informasi. Berdasarkan Model persamaan struktur (SEM), variabel yang paling efektif terhadap perilaku penggunaan APD adalah sikap petani terhadap pestisida diikuti oleh pengetahuan tentang bahaya pestisida, pengalaman keracunan, dan sumber informasi. Keempat variabel ini menjelaskan $85 \%$ perbedaan perilaku dalam penggunaan APD. Studi ini memberikan informasi baru tentang peran mediasi sikap petani terhadap pestisida, pengetahuan tentang bahaya pestisida, pengalaman keracunan, dan sumber informasi dalam penggunaan APD. ${ }^{15}$

\section{SIMPULAN DAN SARAN}

Berdasarkan hasil penelitian dapat disimpulkan pengetahuan responden yang baik tentang alat pelindung diri berhubungan dengan perilaku penggunaan alat pelindung diri saat bekerja, sikap responden yang positif tentang alat pelindung diri tidak berhubungan dengan perilaku penggunaan alat pelindung diri saat bekerja. Disarankan melakukan penelitian kualitatif untuk membantu memahami sikap dan pemikiran pekerja tentang penggunaan APD, selain itu kepada pihak terkait, agar berupaya maksimal meningkatkan kesadaran pekerja tentang Kesehatan dan Keselamatan Kerja (K3) khususnya penggunaan APD.

\section{UCAPAN TERIMA KASIH}

Ucapan terima kasih disampaikan kepada Bapak Nasrul, SKM, M.Kes selaku Direktur Poltekkes Kemenkes Palu, Bapak Sulman selaku Ketua Koperasi Tenaga Kerja Bongkar Muat (TKBM) "Samudera" Pelabuhan Pantoloan atas perkenan dan kerjasama yang baik selama pelaksanaan penelitian.

\section{DAFTAR PUSTAKA}

1. Kasman M. Korelasi Penggunaan Alat Pelindung Diri Dengan Kecelakaan Kerja Pada Crew Drilling. J Iptek Terap. 2016;10(4).

2. Aryantiningsi DS. Kejadian Kecelakaan Kerja Pekerja Aspal Mixing Plant (AMP) \& Batching1. Aryantiningsi DS. Kejadian Kecelakaan Kerja Aspal Mixing Plant (AMP) \& Batching Plant DI PT. LWP Pekanbaru Tahun 2015. 2007;417(1):1195-1197. Plant DI PT. LWP Pekanbaru. 2007;417(1):1195-7.

3. Martiwi R, Koesyanto H, Pawenang ET. Faktor Penyebab Kecelakaan Kerja Pada 
Pembangunan Gedung. Higeia (Journal Public Heal Res Dev [Internet]. 2017;1(4):6171. Available from: http://journal.unnes.ac.id/sju/index.php/higeia

4. International Labour Organization. Meningkatkan Keselamatan dan Kesehatan Pekerja Muda [Internet]. Kantor Perburuhan Internasional , CH- 1211 Geneva 22, Switzerland. International Labour Organization; 2018. Available from: http://www.oit.org/wcmsp5/groups/public/---asia/---ro-bangkok/---ilojakarta/documents/publication/wcms_627174.pdf

5. Kasus Kecelakaan Kerja Tembus 153 Ribu Pada 2020 [Internet]. [cited 2021 Jun 2]. Available from: https://www.cnnindonesia.com/ekonomi/20210215130019-78606341/kasus-kecelakaan-kerja-tembus-153-ribu-pada-2020

6. Kadis: Keselamatan Kerja Harus Terjamin | Metrosulawesi [Internet]. [cited 2021 Jun 2]. Available from: https://metrosulawesi.id/2020/02/15/kadis-keselamatan-kerja-harusterjamin/

7. Undang-undang Republik Indonesia Nomor 36 Tahun 2009 Tentang Kesehatan. 2009.

8. Undang - Undang Republik Indonesia No 13 tahun 2003 Tentang Ketenagakerjaan. 2003.

9. Notoatmodjo S. Promosi Kesehatan dan Perilaku Kesehatan. Jakarta: Rineka Cipta; 2012.

10. Nurzaidah M, Andri M. Hubungan Pengetahuan dan Sikap Dengan Penggunaan APD Pada Pekerja Kasur di Desa Dalaka Kecamatan Sindue Kabupaten Donggala. J Kolaboratif Sains. 2019;1(1):46-55.

11. Aeni HF, Nurfadillah R. Hubungan Antara Pengetahuan Dan Sikap Dengan Praktik Penggunaan APD Pada Petani Pengguna Pestisida. Med Sains Junal IIm Kefarmasian. 2018;3(1):19-30.

12. Asgedom $A A$, Bråtveit $M$, Moen $B E$. Knowledge, attitude and practice related to chemical hazards and personal protective equipment among particleboard workers in Ethiopia: A cross-sectional study. BMC Public Health. 2019;19(1):1-10.

13. Izudi J, Ninsiima V, Alege JB. Use of Personal Protective Equipment among Building Construction Workers in Kampala, Uganda. J Environ Public Health. 2017;2017(November 2015).

14. Rostami F, Afshari M, Rostami-Moez M, Assari M, Soltanian A. Knowledge, attitude, and practice of pesticides use among agricultural workers. Indian J Occup Environ Med [Internet]. 2019 Jan 1 [cited 2021 Jun 2];23(1):42-7. Available from: /pmc/articles/PMC6477942/

15. Bondori A, Bagheri A, Damalas CA, Allahyari MS. Use of a Personal Protective Equipment Towards Pesticide Exposur: Farmers' Attitudes and Determinants of Behavior. Sci Total Environ. 2018;639(October 2018):1156-63. 